\title{
The Effect of Age, Gender, Refractive Status and Axial Length on the Measurements of Hertel Exophthalmometry
}

\author{
Omer Karti ${ }^{1}$, Ozlem B. Selver ${ }^{2}$, Eyyup Karahan ${ }^{*}, 3$, Mehmet O. Zengin ${ }^{4}$ and Murat Uyar ${ }^{3}$ \\ ${ }^{1}$ Torbali State Hospital, Department of Ophthalmology, Izmir, Turkey \\ ${ }^{2}$ Ege University, Department of Ophthalmology, Izmir, Turkey \\ ${ }^{3}$ Sifa University, Department of Ophthalmology, Izmir, Turkey \\ ${ }^{4}$ Izmir University, Department of Ophthalmology, Izmir, Turkey
}

\begin{abstract}
Purpose: To evaluate the normal distribution of exophthalmometric values in Turkish adult population and the effect of age, gender, refractive status and axial length on globe position.

Methods: One hundred and twenty-two males and 114 healthy females with age ranging from 18 to 87 years were included in the study. The study population was recruited from patients presenting to our institution for routine refractive examination. Hertel exophthalmometer was used to measure the degree of ocular protrusion. Effect of age, refractive error, interpupillary distance, and axial length on globe position was detected with linear regression analyses.

Results: The mean Hertel exophthalmometric size was $15.7 \pm 2.6 \mathrm{~mm}$ (range; 11 to $21 \mathrm{~mm}$ ). The mean value for males was $16.1 \pm 2.6 \mathrm{~mm}$ (range; 11 to $21 \mathrm{~mm}$ ), and for females $15.5 \pm 2.6 \mathrm{~mm}$ (range; 11 to $20 \mathrm{~mm}$ ). The mean distance between the lateral rims of the orbit was $102 \pm 5.1 \mathrm{~mm}$ (range; 88 to $111 \mathrm{~mm}$ ). The mean exophthalmometric values were not statistically different in males and females. Age and mean spherical equivalents were negatively correlated with exophthalmometric measurements. Axial length was positively correlated with exophthalmometric measurements.

Conclusion: The exophthalmometric measurement of the eye is affected by the age, spherical equivalent and the axial length. Standard normative values of the Hertel exophthalmometric measurements should be reevaluated with larger samples.
\end{abstract}

Keywords: Axial length, exophthalmometry, spherical equivalent, Turkish population.

\section{INTRODUCTION}

The orbital space contains mainly the eyeball, extraocular musculature, retro-orbital fatty tissue, and vascular structures [1-4]. Enlargement of one or more elements of the orbital tissue or pathological conditions of the orbital walls can cause ocular protrusion [4]. The most common ethological factors for ocular protrusion are thyroid orbitopathy, orbital trauma, and tumors. High axial myopia and lid asymmetry may also result in ocular protrusion [3,5].

Exophthalmometry is one of the routine examination methods for patients with suspected ocular protrusion [6]. There are various devices for exophthalmometric purposes; however, Hertel exophthalmometry is the most commonly used device [7]. Although the normal limits of protrusion of the human eye are accepted to be between 10 and $21 \mathrm{~mm}$, exophthalmometric values have been shown to vary with ethnicity, age, gender, height, weight, body mass index (BMI), orbital parameters, refraction and axial length (AL) of the eye $[1,4,8-18]$.

*Address correspondence to this author at the Narlı Mah. Ecem Sok. Kayısıkent Sitesi, C Blok D:7 Narlıdere, İzmir, Turkey;

Tel: 90232278 8111, 90232278 6804; E-mail: karahaneyup@yahoo.com
The purpose of this study was to determine the normal exophthalmometric values of Turkish healthy adult population and the impact of age, gender, refractive status and $\mathrm{AL}$ on globe position.

\section{MATERIAL AND METHODS}

Healthy individuals, who were randomly selected from the patients presented to our institution, were included in the study. This study was followed the tenets of the Declaration of Helsinki. Hertel exophthalmometer (Hertel exophthalmosmeter K-0161, Inami \& Co. Ltd. japan) was used to measure the degree of ocular protrusion in 236 Turkish adults. The measurements were performed under sunlight for both eyes simultaneously, but only right eye measurements were included in this study. Two observers (OK, MOZ) have obtained all measurements by using the same Hertel exophthalmosmeter. The observers were not privy to each other's findings and the mean of these two measurements was considered for the analysis. All subjects underwent refractive error, and interpupillary distance (IPD) measurements using an objective auto-refractometer (Topcon RK 8000PA, autorefractometer, Topcon, Tokyo, Japan). Axial length measurement was carried out with a Lenstar LS 900 (HAAGSTREIT). Patients with systemic or ocular diseases, 
endocrine or craniofacial abnormalities, or history of orbital trauma were excluded from the study.

SPSS, version 11.6 (SPSS, Inc, Chicago, IL) was used for statistical analysis. t-test was used to compare males and females with regard to age, spherical equivalece, AL, IPD and exophthalmometric values. Chi-square t-test was used to evaluate the effect of gender on eye protrusion. Linear and multiple regression analysis was used to analyze the effect of age, spherical equivalent, and AL on exophthalmometric values.

\section{RESULTS}

A total of 236 eyes of 236 subjects were enrolled in the study. One hundred twenty-two subjects $(51.7 \%)$ were male and 114 subjects $(48.3 \%)$ were female. Mean age was $44.1 \pm 14.6$ years (range: 18 to 87 years) in male population, and $45.9 \pm 14.3$ years (range: $18-85$ years) in female population $(\mathrm{p}=0.316)$. Mean Hertel exophthalmometric measurements for the whole population was $15.8 \pm 2.6 \mathrm{~mm}$ (range: 11 to $21 \mathrm{~mm}$ ), where mean value was found as $16.1 \pm 2.6 \mathrm{~mm}$ and $15.5 \pm 27 \mathrm{~mm}$ for male and female populations, respectively $(\mathrm{p}=0.062)$

Age was found to mildly affect the Hertel measurements $\left(\mathrm{R}^{2}=0.098, \mathrm{p}=0.000\right)$ to a small extent.

Spherical equivalents were negatively correlated with exophthalmometric measurements. Every 1.7 diopter increase of spherical equivalent caused a decrease of $1.0 \mathrm{~mm}$ in exophthalmometric values. This result was found to be statistically significant $\left(\mathrm{R}^{2}=0.028, \mathrm{p}=0.01\right)$.

Every $4.7 \mathrm{~mm}$ increase in AL was associated with a 1 $\mathrm{mm}$ increase in exophthalmometric value. There was a moderate correlation between AL and Hertel measurements $\left(\mathrm{R}^{2}=0.191, \mathrm{p}=0.000\right)$.

There was no relation between IPD and Hertel measurements $\left(\mathrm{R}^{2}=0.022, \mathrm{p}=0.000\right)$.

The age, Hertel values, spherical equivalents, AL and IPD of all subjects are shown in Table 1.

Multiple regression analysis also revealed a significant correlation between Hertel measurements and age, and spherical equivalent and AL (Table 2).

\section{DISCUSSION}

In the adult human, the total volume of the orbit is about $30 \mathrm{ml}$ including the eyeball, fat tissue, muscles, and vascular structures. An excess of orbital tissues may result in eyeball protrusion known as exophthalmos [1,4].

Exophthalmometry is a simple procedure for both the diagnosis and follow up of several orbital pathologies. Hertel exophthalmometer is a cheap, simple and portable device so it is the most commonly used device for exophthalmometric measurements worldwide. Although it gives reliable results, several studies have noticed that exophthalmometric values may vary according to various factors such as ethnicity, age, gender, height, weight, orbital parameters, and refraction [1, 4, 9-18].
Table 1. Age, mean spherical equivalent, axial length, IPD and exophthalmometric measurements of male and female population.

\begin{tabular}{|c|c|c|c|}
\hline & $\begin{array}{c}\text { Male } \\
(\mathbf{n = 1 2 2})\end{array}$ & $\begin{array}{c}\text { Female } \\
(\mathbf{n = 1 1 4})\end{array}$ & P Value \\
\hline \hline Age (years) & $44.1 \pm 14.6$ & $45.9 \pm 14.3$ & 0.316 \\
\hline Spherical equivalent & $0.49 \pm 1.55$ & $0.38 \pm 1.49$ & 0.194 \\
\hline Axial length (mm) & $23.1 \pm 1.1$ & $23.4 \pm 1.5$ & 0.066 \\
\hline IPD (mm) & $63.6 \pm 3.2$ & $64.2 \pm 3.9$ & 0.123 \\
\hline Exophthalmometric value (mm) & $16.1 \pm 2.6$ & $15.5 \pm 2.6$ & 0.062 \\
\hline
\end{tabular}

IPD: Interpupillary distance.

Table 2. Multipl regression analysis for the relation between Hertel measurements and age, spherical equivalent, axial length and IPD.

\begin{tabular}{|c|c|c|c|}
\hline & Standardized Coefficients & \multirow{2}{*}{ t } & \multirow{2}{*}{ Sig. } \\
\cline { 2 - 3 } & & & \\
\hline \hline Age & -0.278 & 1.278 & 0.202 \\
\hline Spherical equivalent & -0.120 & -4.506 & 0.000 \\
\hline Axial length & 0.035 & -1.931 & 0.035 \\
\hline IPD & 0.233 & 3.868 & 0.000 \\
\hline IPD: Interpupillary distance & & & \\
& & &
\end{tabular}

Being the most important parameter, skeletal structure differences between ethnicity, age and gender affects the exophthalmometric values. Based on this knowledge, many investigators tried to determine the normative values of exophthalmometric measures in distinct populations $[13,19]$.

Our results demonstrate that Turkish adult males and females ocular protrusion values are $16.2+2.6 \mathrm{~mm}$ and 15.2 $\pm 2.5 \mathrm{~mm}$, respectively. The upper normal limits are $21 \mathrm{~mm}$ (male) and $20 \mathrm{~mm}$ (female). Our measurement results for both genders were nearly $2.5 \mathrm{~mm}$ higher than the previous reports on Turkish samples [4,9]. Both studies included subjects from the north and northeast part of Turkey, respectively, whereas our study was carried out in a city, which is in the west part of Turkey. Since our country consisted of various ethnic groups, Hertel measurements may show different results in different regions.

Different studies showed various results regarding the relation between age and Hertel measurements. Several studies demonstrated a decrease in ocular protrusion values after the age of 20 years according to the involutional orbital soft tissue atrophy [16, 20, 21]. Kashkouli et al. [20] and Nath et al. [21] demonstrated that protrusion of the eyeball significantly increased with aging in children and teenagers, but decreased with aging in adults. Fledelius et al. [11] showed that the adult protrusion values are reached in late teenage years; but thereafter remain stable. Chan et al. [6] 
reported that measurements were not statistically different in age groups in both sexes. In our study, there was a low correlation between age and Hertel measurements.

Gender factor in ocular protrusion is controversial. Migliori et al. [1] and Dunsky et al. [22] reported a statistically significant increase in ocular protrusion values in males. Fledelius et al. [11] attributed the higher male ocular protrusion to the greater body structure. In contrast, other researchers did not find a significant gender difference in ocular protrusion $[4,20]$. In our study, there was no statistically significant difference $(\mathrm{p}=0.123)$ between the two genders in accordance to finding in the literature.

In most studies, high myopia $(<-6 \mathrm{D})$ was excluded to avoid the pseudo-proptosis effect of this condition $[4,9,20]$. In studies that evaluated the spherical equivalents and exophthalmometric value relation, no correlation between these two parameters was noted $[6,11]$. In our study, we also excluded high myopia patients from the study and we found a negative correlation between spherical equivalents and exophthalmometric measurements, which is different from the previous reports.

Determining the relation between $\mathrm{AL}$ and Hertel measurements is an important issue. Chan et al. [6] demonstrated a statistically significant positive correlation between $\mathrm{AL}$ and ocular protrusion. They reported that every $4 \mathrm{~mm}$ increase in $\mathrm{AL}$ was associated with a $1 \mathrm{~mm}$ increase in exophthalmometric measurement. This correlation suggests that Hertel measurements should be corrected with regards to AL measurements. In our study, we also elucidated the relationship between ocular protrusion and AL. We found that every $4.7 \mathrm{~mm}$ increase in AL was associated with a 1 $\mathrm{mm}$ increase in exophthalmometric value. The relation of Hertel measurements and AL is still not well described and there is a need for more studies to obtain standardization of Hertel measurements and AL relation.

In summary, many factors including age, spherical equivalent and AL may have significant effects on ocular protrusion values. Consequently, larger, multiscale and prospective studies can provide much more valuable data about exophthalmometric measurements.

\section{CONFLICT OF INTEREST}

The authors confirm that this article content has no conflict of interest.

\section{ACKNOWLEDGEMENTS}

Declared none.
[21] Nath K, Gogi R, Rao GS, Krishna G, Zaidi N. Normal exophthalmometry. Indian J Ophthalmol 1977; 25: 47-52.

\section{REFERENCES}

[1] Migliori ME, Gladstone GJ. Determination of the normal range of exophthalmometric values for black and white adults. Am J Ophthalmol 1984; 98: 438-42.

[2] Naugle TC Jr, Couvillion JT. A superior and inferior orbital rimbased exophthalmometer (orbitometer). Ophthalmic Surg 1992; 23: 836-7.

[3] Osuobeni EP, al-Harbi AA. Normal values of ocular protrusion in Saudi Arabian male children. Optom Vis Sci 1995; 72: 557-64.

[4] Bilen H, Gullulu G, Akcay G. Exophthalmometric values in a normal Turkish population living in the northeastern part of Turkey. Thyroid 2007; 17: 525-8.

[5] Kim IT, Choi JB. Normal range of exophthalmos values on orbit computerized tomography in Koreans. Ophthalmologica 2001; 215 : 156-62.

[6] Chan W, Madge SN, Senaratne T, et al. Exophthalmometric values and their biometric correlates: The Kandy Eye Study. Clin Experiment Ophthalmol 2009; 37: 496-502.

[7] Chang AA, Bank A, Francis IC, Kappagoda MB 1995 Clinical exophthalmometer. Aust N Z J Ophthalmol 23: 315-8.

[8] Wright JE. Proptosis. Ann R Coll Surg Engl 1970’ 47: 323-34.

[9] Beden U, Ozarslan Y, Ozturk HE, Sonmez B, Erkan D, Oge I. Exophthalmometry values of Turkish adult population and the effect of age, sex, refractive status, and Hertel base values on Hertel readings. Eur J Ophthalmol 2008; 18: 165-71.

[10] Quant JR, Woo GC. Normal values of eye position in the Chinese population of Hong Kong. Optom Vis Sci 1992; 69: 152-8.

[11] Fledelius HC, Stubgaard M. Changes in eye position during growth and adult life as based on exophthalmometry, interpupillary distance, and orbital distance measurements. Acta Ophthalmol 1986; 64: 481-6.

[12] Smolders MH, Graniewski-Wijnands HS, Meinders AE, Fogteloo AJ, Pijl H, de Keizer RJ. Exophthalmos in obesity. Ophthalmic Res 2004; 36: 78-81.

[13] Nucci P, Brancato R, Bandello F, Alfarano R, Bianchi S. Normal exophthalmometric values in children. Am J Ophthalmol 1989; 108: 582.

[14] Sodhi P, Gupta VP, Pandey RM. Exophthalmometric values in a normal Indian population. Orbit 2001; 20: 1-9.

[15] Ahmadi H, Shams PN, Davies NP, Joshi N, Kelly MH. Age-related changes in the normal sagittal relationship between globe and orbit. J Plast Reconstr Aesthet Surg 2007; 60: 246-50.

[16] Kaye SB, Green JR, Luck J, Lowe KJ. Dependence of ocular protrusion, asymmetry of protrusion and lateral interobital width on age. Acta Ophthalmol 1992; 70: 762-5.

[17] Swan LK, Stephan CN. Estimating eyeball protrusion from body height, interpupillary distance, and inter-orbital distance in adults. J Forensic Sci 2005; 50: 1528 .

[18] Bolanos Gil deMontes F, Perez Resinas FM, Rodriguez Garcia M, Gonzalez Ortiz M. Exophthalmometry in Mexican adults. Rev Invest Clin 1999; 51: 341-3.

[19] Tsai CC, Kau HC, Kao SC, Hsu WM. Exophthalmos of patients with Graves' disease in Chinese of Taiwan. Eye 2006; 20: 569-73.

[20] Kashkouli MB, Nojomi M, Parvaresh MM, Sanjari MS, Modarres M, Noorani MM. Normal values of hertel exophthalmometry in children, teenagers, and adults from Tehran, Iran. Optom Vis Sci 2008; 85: 1012-7.

[22] Dunsky IL. Normative data for hertel exophthalmometry in a normal adult black population. Optom Vis Sci 1992; 69: 562-4. exophthalmometry: a comparative study of the Lued and Hertel 